\title{
The Cultural Evolution of Words and Other Thinking Tools
}

\author{
D.C. DENNETT \\ Center for Cognitive Studies, Tufts University, Medford, Massachusetts 02155 \\ Correspondence: daniel.dennett@tufts.edu
}

\begin{abstract}
The emergence of language and culture is one of the major transitions in evolution (Maynard Smith and Szathmary 1995), and the key to the cumulative nature of cultural transmission in Homo sapiens as contrasted with other species is the digital nature of language, which permits semi-understood designed entities to be preserved and transmitted. Phonemes are not the only systems of self-correcting (digitized) norms; other "alphabets" of practices also contribute to high-fidelity preservation of cultural products.
\end{abstract}

Anthropocentrism often distorts our vision of evolution, encouraging us to see our own case as special, but there are objective grounds for maintaining that the emergence of language and culture is one of the major transitions in evolution (Maynard Smith and Szathmary 1995). The key to the cumulative nature of cultural transmission in Homo sapiens, as contrasted with cultural transmission in other species, is the digital nature of language, which permits semi-understood designed entities to be preserved and transmitted. Phonemes and written letters are not the only systems of self-correcting (digitized) norms; other "alphabets" of practices also contribute to high-fidelity preservation of cultural products despite variable comprehension. The role of comprehension in human culture is often overestimated, and the best way to see the spectrum of possibilities is to adopt the perspective of memes (Dawkins 1976), cultural items that replicate with varying amounts of input from intelligent vectors. Words can be seen to be the foundational memes that permit the accumulation and transmission of ever more elaborate artifacts and practices.

\section{CULTURE AS A MAJOR TRANSITION IN EVOLUTION}

According to calculations by Paul MacCready (1999), at the dawn of human agriculture 10,000 years ago, the worldwide human population plus their livestock and pets was $\sim 0.1 \%$ of the terrestrial vertebrate biomass. Today, he calculates, it is $98 \%$ ! (Most of that is cattle.) His reflections on this amazing development are worth quoting:

Over billions of years, on a unique sphere, chance has painted a thin covering of life-complex, improbable, wonderful and fragile. Suddenly we humans ... have grown in population, technology, and intelligence to a position of terrible power: we now wield the paintbrush. (MacCready 1999, p. 19).

Some biologists are convinced that we are now living in the early days of a sixth great mass extinction event (the "Holocene"), to rival the Permian-Triassic extinction $\sim 250$ million years ago and the Cretacious-Tertiary extinction $\sim 65$ million years ago. And because, as MacCready puts it so vividly, we wield the paintbrush, this mass extinction, if it occurs, would go down in evolutionary history as the first to be triggered by the innovations in a single species. Compared to the biologically "sudden" Cambrian explosion, which occurred over several million years $~ 530$ million years ago, what we may call the MacCready explosion has occurred in $\sim 10,000$ years, or $\sim 500$ human generations (of course, thousands of prior generations were required to set up many of the conditions that made this possible). There is really no doubt, then, that it has been the rapidly accumulating products of cultural evolution-technology and intelligence, as MacCready says - that account for these unprecedented transformations of the biosphere. So Maynard Smith and Szathmary (1995) are right to put language and culture as the most recent of the "major transitions of evolution":

$$
\begin{aligned}
& \text { replicating molecules } \rightarrow \text { populations of molecules in } \\
& \quad \text { compartments } \\
& \text { independent replicators } \rightarrow \text { chromosomes } \\
& \text { RNA } \rightarrow \text { DNA and protein } \\
& \text { prokaryotes } \rightarrow \text { eukaryotes } \\
& \text { asexual clones } \rightarrow \text { sexual populations } \\
& \text { protists } \rightarrow \text { animals, plants, fungi } \\
& \text { solitary individuals } \rightarrow \text { colonies } \\
& \text { primate societies } \rightarrow \text { human societies [with language and } \\
& \quad \text { culture] (Maynard Smith and Szathmary 1995, p. 6) }
\end{aligned}
$$

Behavioral-perceptual transmission (as contrasted with genetic transmission) occurs in many species of animals (Avital and Jablonka 2000), and behaviors earlier deemed genetically inherited "instincts" have been shown primarily by cross-fostering experiments to be mediated by behavioral and perceptual interactions between parent and offspring, not by genes. As Richerson and Boyd (2006) show, just as the standard information highway, the vertical transmission of genes, was optimized during billions of years, the second information highway from parents to offspring had to evolve under rather demanding conditions; however, once this path of vertical cultural transmission had been 
established and optimized, it could be invaded by "rogue cultural variants," horizontally or obliquely transmitted cultural items that do not have the same probability of being benign. (The comparison to spam on the internet is hard to avoid.) These rogue cultural variants are what Richard Dawkins (1976) calls memes, and although some of them are bound to be pernicious - parasites, not mutualists - others are profound enhancers of the native competences of the hosts they infect. One can acquire huge amounts of valuable information of which one's parents had no inkling, along with the junk and the scams.

Only in one species, Homo sapiens, has transmission by replication of nongenetic information taken off. In us, culture accumulates recursively, explosively, leaping thousands of miles and dozens of centuries in single steps. This hyperpotent variety of cultural evolution depends, I will argue, on language and more specifically on features of words, a category of cultural replicant found only in human beings (and, marginally, degenerately, in some of their domesticated animals and pets, such as parrots). It is words, I will argue, that make possible a novel system of design control never before instantiated on the planet, the difference dramatized by the comparison between the termite castle and Antonio Gaudí's La Sagrada Famiglia church in Barcelona (Fig. 1). These two animal artifacts, so outwardly similar in shape, are produced by fundamentally different processes. In the case of the termite castle, "local rules generate global order," as the slogan has it: Individual termites follow rigid rules for moving and depositing building material by detecting local pheromone signals, and no organism has, or needs, a vision or blueprint of the whole structure. In the case of La Sagrada Famiglia, there was an "intelligent designer," an individ- ual, Antonio Gaudí, who did have a guiding vision and did draw up plans; the control of the building flowed from the top down, through verbal representations to subordinates and thence to their subordinates. The design and construction could not have proceeded without elaborate systems of symbolic communication.

\section{THE NATURE OF WORDS}

What then are words? Do they even exist? This might seem to be a fatuous philosophical question, composed as it is of the very items it asks about, but it is, in fact, exactly as serious and contentious as the claim that genes do or do not really exist. Yes, of course, there are sequences of nucleotides on DNA molecules, but does the concept of a gene actually succeed (in any of its rival formulations) in finding a perspicuous rendering of the important patterns amidst all that molecular complexity? If so, there are genes; if not, then genes will in due course get thrown on the trash heap of science along with phlogiston and the ether, no matter how robust and obviously existing they seem to us today. We live in the Age of the Gene (or the Atomic Age), but atoms have turned out not to be atomic, and the genes of Mendel are being shouldered aside, in some regards, by other ways of cutting nature at its joints (Haig 2006). Similarly, there are vocalizations that do an admirable job of purveying information from one person to another; their "moving parts" seem best described as words (or lexical items in the somewhat more technical idiom of Jackendoff [2002]). Genes, according to George Williams (1966, p. 25) are best seen as the information carried by the nucleotide sequences, not the nucleotide sequences themselves, a point that is nicely echoed by such observations as
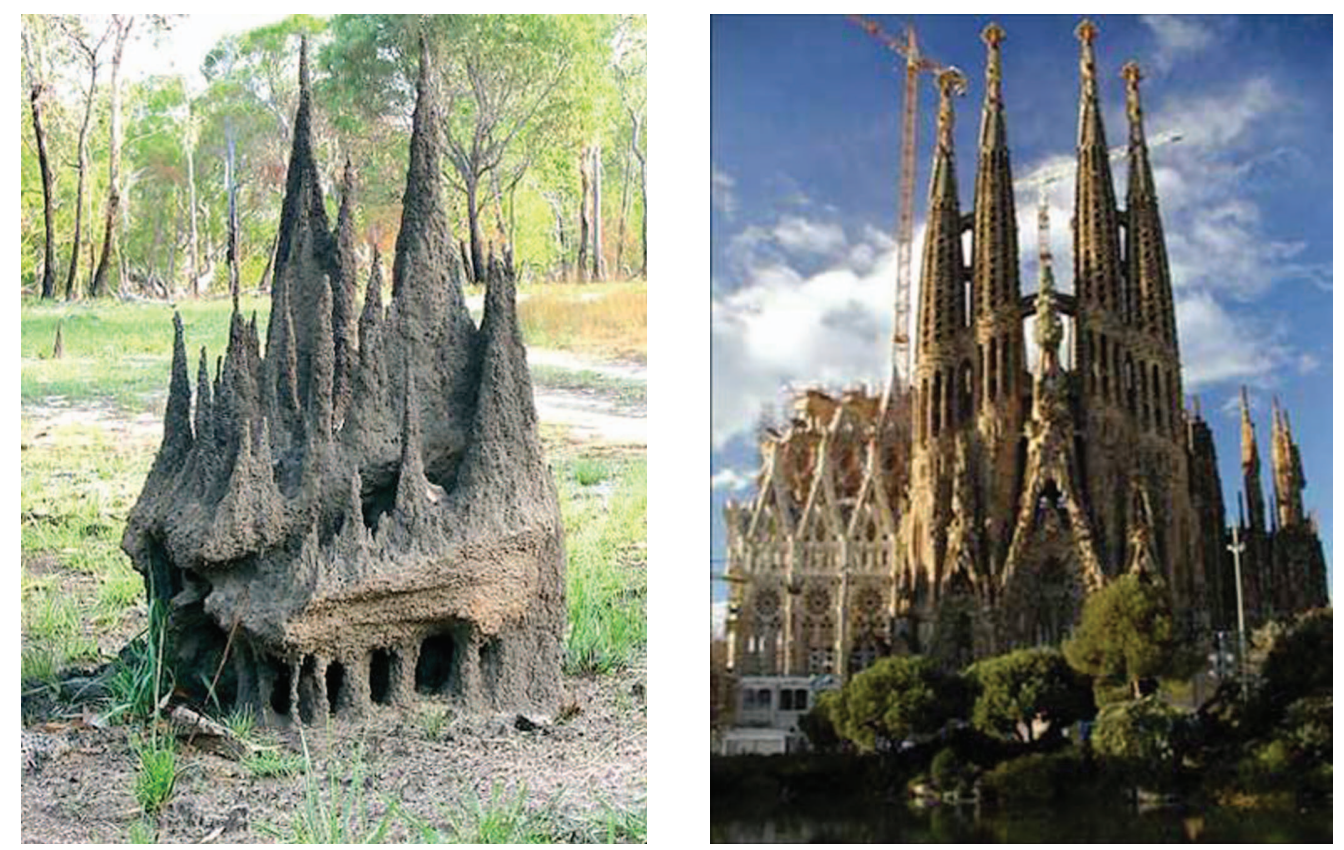

Figure 1. (Left) Termite castle, (right) Antonio Gaudí's La Sagrada Famiglia church in Barcelona (courtesy of Diario di Viaggio). 
these: A promise or a libel or a poem is identified by the words that compose it, not by the trails of ink or bursts of sound that secure the occurrence of those words. Words themselves have physical "tokens" (composed of uttered or heard phonemes, seen in trails of ink or glass tubes of excited neon or grooves carved in marble), and so do genes, but these tokens are a relatively superficial part or aspect of these remarkable information structures, capable of being replicated, combined into elaborate semantic complexes known as sentences, and capable in turn of provoking cognitive, emotional, and behavioral responses of tremendous power and subtlety.

Words are such familiar parts of our experience that we seldom notice how much less "concrete" they are than the rest of the furniture of the everyday world. A chair or teacup or rainbow may be made of wood, porcelain, or water droplets, but a word is an abstraction, like a method or style, a mathematical technique, or a move in a game. What is castling (in chess) "made of"? What is long division made of, or Bayesian statistics? Or songs or jokes or crossword puzzles or patents or laws or taboos? What is software made of? The human world contains a bounty of manipulable abstractions that are taken for granted and that have no counterpart in the behavioral worlds of other animals. What are words? They are not just sounds, or marks, or even symbols. They are memes (Dawkins 1976; Dennett 1991, 1995, 2006). Words are that subset of memes that can be pronounced.

The best way to see how the concept of memes clarifies and extends our understanding of the role of culture in human evolution is to compare the meme's eye perspective to the traditional wisdom- "common sense"-according to which culture is composed of various valuable practices and artifacts, inherited treasures, in effect, that are recognized as such (for the most part) and transmitted deliberately (and for good reasons) from generation to generation. Cultural innovations that are intelligently designed are esteemed, protected, tinkered with, and passed on to the next generation, whereas accidental or inadvertent combinations of either action or material are discarded or ignored as junk. This is basically an economic model, where possessions, both individual and communal, are preserved, repaired, and handed down. This familiar perspective on culture is for the most part uncritically adopted by cultural historians, anthropologists, and other theorists, and it meshes nicely, it seems, with evolutionary biology. Cultural innovations, like genetic innovations, have to "pay for themselves" to survive, by providing a fitness boost to their possessors. A new way of catching fish, whether genetically transmitted as an innate instinct or cultural transmitted as a learned practice, will go to fixation only if it is better than the old ways of catching fish.

Many celebrated elements of human culture fit this model precisely. We can even identify the intelligent designers responsible for the innovations and carve their names on the friezes of our libraries: Euclid, Pythagoras, Descartes, Newton, Einstein, Curie, Homer, Shakespeare, Austen. But there is a problem: Many of our most valuable cultural treasures have no identifiable author and almost certainly were cobbled together by many largely unwitting minds over long periods of time. Nobody invented words or arithmetic or music or maps or money. These apparent exceptions to the traditional model are typically not seen as a serious problem. The requirement of intelligent authorship can be maintained by distributing it over indefinitely many not-so-intelligent designers whose identities are lost to us only because of gaps in the "fossil record" of culture. And we can acknowledge that many of the improvements accumulated over time were "dumb luck" accidents that nevertheless got appreciated and preserved. With these concessions, the traditionalist can avoid acknowledging what ought to seem obvious: These excellent things acquired their effective designs the same way plants and animals and viruses acquired theirs - they evolved by natural selection, but not genetic natural selection.

The dual inheritance model, in which adaptations - fitness-enhancing innovations - can be transmitted vertically either genetically or culturally from parent to offspring, and rogue cultural variants or memes can also be transmitted obliquely or horizontally, takes us almost all the way to the memetic perspective. Rogue cultural variants need not be fitness-enhancing to their hosts in order to flourish, although of course they may be. Like other endosymbionts, they may be parasites that actually reduce fitness, or they may be neutral commensals or benign mutualists. The key improvements, then, of the memetic perspective are its recognition that

1. Excellently designed cultural entities may, like highly efficient viruses, have no intelligent design at all in their ancestry.

2. Memes, like viruses and other symbionts, have their own fitness. Those that flourish will be those that better secure their own reproduction, whether or not they do this by enhancing the reproductive success of their hosts by mutualist means.

Our paradigmatic memes, words, would seem to be mutualists par excellence, because language is so obviously useful, but we can bear in mind the possibility that some words may, for one reason or another, flourish despite their deleterious effects on this utility. (Pressed once by a student for a good example, I replied "Well, like, there might be, like, a catchphrase or, like, a verbal tic that was, like, a bad but infectious habit that could, like, spread through a subpopulation and, like, even go to fixation without, like, providing any communicative benefit at all." The student replied that he understood the point but, like, could I please give him an example?) The "syntactocentric" (Jackendoff 2002) perspective on language that has dominated theoretical linguistics since the pioneering efforts of Chomsky (see, e.g., Chomsky 1957, 1980) tends to obscure the fact that words have an identity that is to a considerable extent language-independent. Like lateral or horizontal gene transfer, lateral word transfer is a ubiquitous feature, and it complicates the efforts of those who try to identify languages and place them unequivocally in glossogenetic trees. English and French, for instance, share no ancestor later than proto-Indo-European (see Fig. 2) but have many words in common that have migrated 


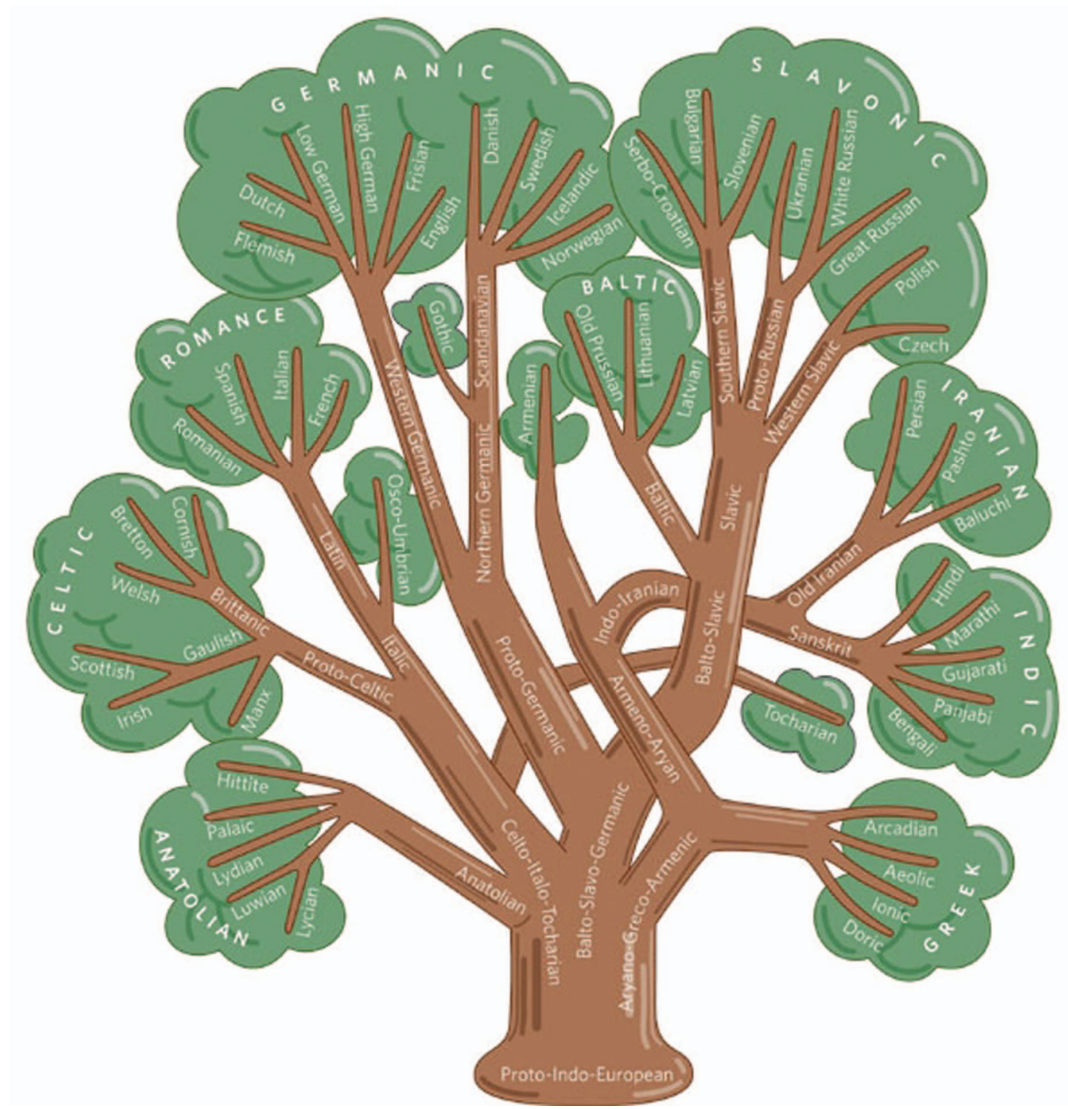

Figure 2. The tree of Proto-Indo-European languages (reprinted, with permission, from Fitch 2007 [C Nature Publishing Group].)

back and forth since their divergence (cul-de-sac and baton, le rosbif and le football, among thousands of others). Just as gene lineages prove to be more susceptible to analysis than organism lineages, especially when we try to extend the tree of life image back before the origin of eukaryotes (WF Doolittle, this volume), so word lineages are more tractable and nonarbitrary than language lineages (for recent work on the evolution of words, see Fitch 2007; Lieberman et al. 2007; Pagel et al. 2007).

Although words now have plenty of self-appointed guardians, usage mavens, and lexicographers who can seldom resist the temptation to attempt to legislate on questions of meaning and pronunciation, most words - almost all words aside from coinages tied tightly to particular technical contexts - are better seen as synanthropic, like rats, mice, pigeons, cockroaches, and bedbugs, rather than domesticated. They have evolved to thrive in human company, but nobody owns them, and nobody is responsible for their welfare. The exceptions, such as "oxygen" and "nucleotide," are anchored by systematic definitions fixed by convention and reproduced in the young by deliberate instruction, rehearsal, and memorization. Some domesticated species of animals - notoriously, laying hens - would become extinct without human assistance with their reproduction, and domesticated words can become extinct when the technical contexts for which they were conventionally defined fall into disuse. Who today knows what a martingale or a brigantine is without looking in a dictionary? Other terms survive with related meanings, wearing their ancestry on their sleeves: Carriage return and carbon copy are recent examples. Historical inertia permits clearly suboptimal designs to persist. English and German have appropriately terse monosyllabic words - now and jetzt - where the French and the Italians have to make do with trisyllabic indicators of the moment: maintenant and adesso. (We English often ignore this economy of course, favoring such long-winded oxymorons as "at this point in time"; our purposes are many, and brevity is seldom the determining value.)

\section{WORDS AND OTHER DIGITIZED CULTURAL ELEMENTS}

Words have one feature that has a key role in the accumulation of human culture: They are digitized. That is, norms for their pronunciation permit automatic - indeed involuntary-proofreading, preventing transmission errors from accumulating in much the way the molecular machines that accomplish gene replication do. A famous written example is due to Oliver Selfridge (Fig. 3). An English speaker will read this as "THE CAT" even though the second and fifth symbol are exactly the same intermediate shape. Spoken words are also automatically shoe- 


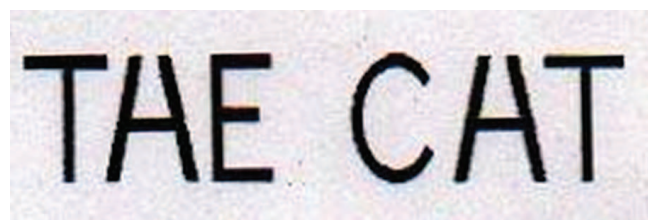

Figure 3. Demonstration of involuntary use of context in correcting to norms. (Adapted from Oliver Selfridge.)

horned into phonemic sequences, depending on the language of the hearer. English-speaking audiences have no difficulty reproducing with perfect accuracy "mundify the epigastrium" on a single hearing, even when they have no inkling of what it could mean (soothe the lining of the stomach - a slang term for "have a drink" in some quarters), but they are unable to reproduce accurately the sounds that might be transliterated as "fnurglzhnyum djyukh psajj." No matter how loudly and clearly articulated, this sequence of vocal sounds has no automatic decomposition into phonemes of English. Even nonsense ("the slithy toves did gyre and gimble in the wabe") can be readily perceived and accurately transmitted, thanks to this system of norms. A similar phenomonon can also be seen to occur at higher, semantic levels of analysis, where norms can be relied upon, in the absence of understanding, to stabilize information for replication. For instance, information about kayaks is stored in Inuit brains and in kayaks but only on the tacit assumption that any kayak observed is or approximates the norm of a good kayak (Richerson and Boyd 2006). Speaking of Polynesian canoes, the French philosopher Alain observed

Every boat is copied from another boat... . Let's reason as follows in the manner of Darwin. It is clear that a very badly made boat will end up at the bottom after one or two voyages, and thus never be copied... . One could then say, with complete rigor, that it is the sea herself who fashions the boats, choosing those which function and destroying the others (Alain 1908, quoted in Rogers and Ehrlich 2008).

It is this transmission of competence without comprehension that lies at the heart of all evolutionary processes of natural selection (Dennett 2009), and it is what permits human culture to accumulate geometrically while other animal traditions are barely additive. It is no mere coincidence that digitization also lies at the heart of computer engineering.

Words are not just like software viruses; they are software viruses, a fact that emerges quite uncontroversially once we adjust our understanding of computation and software. This is made easier for our imaginations by the recent development of Java, the software language that can "run on any platform" and hence has moved to something like fixation in the ecology of the Internet. The intelligent composer of Java applets (small programs that are downloaded and run on individual computers attached to the Internet) does not need to know the hardware or operating system (Mac, PC, Linux, etc.) of the host computer because each computer downloads a Java Virtual Machine (JVM), designed to translate automatically between Java and the hardware, whatever it is. The JVM is "transparent" (users seldom if ever encounter it or even suspect its existence), automatically revised as needed, and (relatively) safe; it will not permit rogue software variants to commandeer your computer. Similarly, when you acquire a language, you install, without realizing it, a Virtual Machine that enables others to send you not just data, but other virtual machines, without their needing to know anything about how your brain works. It is the English Virtual Machine or EVM (in English speakers) that automatically "fixes" the "pinched" H and the "open-ended" A in Selfridge's display (Fig. 3) and that betrays its presence in the Stroop task (Stroop 1935) by interfering with the task of identifying the colors in which the words in Figure 4 are printed. These are but a few of the myriads of microhabits that become imposed on a brain that installs the EVM.

This fact is particularly striking when we compare the practices of psychologists dealing with human subjects and their practices when dealing with other animals. As Jackendoff (2002) has pointed out, it can take hundreds or even thousands of training trials to get animals to perform a new experimental task that can be taught to human subjects in a few sentences of initial briefing. Give your subjects a handful of practice trials and they will perform flawlessly, having constructed a temporary habit that can be abandoned or adjusted as readily as it was adopted. This spectacular combination of plasticity and reliability is unparalleled in the nonhuman world, and it depends on the reliable and projectible effects of dozens of individual informational packets - words - being downloadedheard - in a few seconds and thereupon implemented. We can readily share novel competences whether we have laboriously acquired them by trial and error or have been given them by others: How to make a cherry pie, tie a bowline, solve Sudoku puzzles, spell "epigastrium." This is the stable base of reliably reproducible elements from which we construct our knowhow and our comprehension.

Words are not just sounds or shapes. As Jackendoff (2002) demonstrates, they are autonomous, semi-independent informational structures, with multiple roles in cognition. They are, in other words, software structures, like Java applets. Unlike Java applets, they are designed by

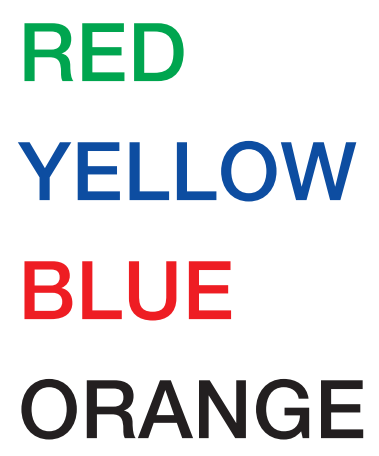

Figure 4. Stroop task: Identify the colors of the printed words as fast as possible (Stroop 1935). 
blind evolution, not intelligent designers, and they get installed by repetition, either by deliberate rehearsal or via several chance encounters. The first time a child hears a new word, it may scarcely register at all, attracting no attention and provoking no rehearsal; the second time the child hears the word, it may be consciously recognized as somewhat familiar or it may not, and in either case, its perception will begin laying down information about context, about pronunciation, and even about meaning. An average six year old has a vocabulary in the range of 5000 words, acquired in $\sim 2000$ days. Some of these words are explicitly taught to them (Johnny, this is a truck - say truck!), but most are not even deliberately adjusted in use (two men, Johnny, not two mans) and yet children reliably acquire remarkably uniform understanding and usage. Controversy rages over how to characterize the native endowment that makes this possible (is Chomsky's Language Acquisition Device a "module" and what information does it contain at the outset?). However, until these issues are sorted out, we can safely note with Deacon (1997) that the genetic evolution of human brains in response to the innovative behavior of language must be a response to the cultural evolution of words during many thousands (but not millions) of years to hold their own in the competition for rehearsal time and storage space in human brains. Cultural evolution is in principle, but not always in fact, much swifter than genetic evolution, because generation times in the former are measured in seconds, not decades. It is a truism in computer engineering that software development leads hardware development, and this principle has its parallel here: It is much easier for language applets - words and their associated informational structures - to accommodate themselves to the constraints of brain architecture than for brains to accommodate themselves to the demands of language.

\section{THE MEMETIC PERSPECTIVE}

With this brief survey of words as memes in hand, let us compare the traditional perspective on cultural evolution with the memetic perspective. Recall that the traditional view is an economic model, of possessions treasured and passed on. The memetic model does not deny the truth of the traditional model; it simply restricts it to one end of the spectrum of possible relations between cultural items and human intelligence and comprehension, including it as a limiting case, in which intelligent, appreciative minds have a strong role.

\begin{tabular}{ll}
\hline Traditional model & Memetic model \\
\hline good things & good, bad, and so-so things \\
invented with insight & insight from 0 to genius \\
valued & value from -100 to +100 \\
passed on with improvements & passed on with mutations \\
(an economic model) & (an economic model as a \\
& limiting case) \\
\hline
\end{tabular}

Darwin himself provides valuable insights into the variable role of intelligence in his introductory discussion in On the Origin of Species (see Darwin 1859). He begins with "methodical selection" in which plant and animal breeders with (relatively) clear intentions and expectations set out to improve the breed. He then notes that before methodical selection, there was "unconscious selection" in which human domesticators inadvertently created selection pressures, breeding their favorites without intending thereby to create any long-term adjustments to the variety. The role of intelligence is indirect in such cases and can even be orthogonal to the results obtained: Undesirable traits are often unconsciously selected. The role of intelligence is reduced to nil in Darwin's third step, natural selection, in which the vicissitudes of nature do all the culling. ${ }^{1}$ We should expect to see all these phenomena in cultural evolution as well. And even if, as many believe, the vast majority of cultural practices and artifacts that persist are beneficial or at any rate not harmful to those who are their vectors, we should adopt a neutral framework from which to measure this claim: One that considers the fitness of the cultural replicators independently of the fitness of their hosts.

This neutral framework is also a valuable antidote to the ubiquitous error of overattributing understanding and intent to those who benefit from the behaviors they regularly engage in, whether these are "instincts" supplied by genes or practices supplied by memes. As the examples of the Inuit kayak or the Polynesian canoe illustrate, the brute presence - survival — of the craft is a more reliable measure of its good design than any insights its current owner may have, and this is as true of "sophisticated" designers as it is of artisans. Amory Lovins (2002) has spoken of the "infectious repetitis" that afflicts car designers; what has worked in the past is routinely assumed by automotive engineers to be optimal, often without any serious consideration of the prospect that improvements might be available.

\section{CONCLUSION}

The Gospel of John opens with "In the beginning was the word..." and if construed as a claim about human intelligent design, it is surely correct: Language, and especially the use of language to communicate and critique and explain design options, is a precondition for the creation and spread of elaborate artifacts. Not surprisingly, for thousands of years, our model of all design processes has been anthropocentric: The word-enabled activity of human designers. Darwin overthrew all that and established the priority of design processes that are not intelligent and that proceed without representationin words or other symbols - of the reasons they uncover (Dennett 2009). Words are, in fact, a very recent innovation, themselves almost entirely the products of natural selection, not intelligent design. They made possible processes of design and construction unprecedented in

\footnotetext{
${ }^{1}$ Darwin's use of methodical and unconscious selection as bridging cases to gently introduce natural selection was a brilliant bit of pedagogy, but these passages can lead to a serious misconstrual: Both methodical and artificial selection should be seen as special cases of natural selection, not alternatives to it. They are instances of natural selection in which the psychological states of one species, H. sapiens, has a particularly focused role in the selection pressure on another species.
} 
the tree of life, illustrated here by the hugely different examples of a termite castle and Gaudí's La Sagrada Famiglia (Fig. 1), and thus their emergence is truly one of the major transitions of evolution.

\section{REFERENCES}

Avital E, Jablonka E. 2000. Animal traditions: Behavioural inheritance in evolution. Cambridge University Press, Cambridge.

Chomsky N. 1957. Syntactic structures. Mouton, The Hague.

Chomsky N. 1980. Rules and representations. Behav Brain Sci 3: $1-15$.

Darwin C. 1859. On the origin of species by means of natural selection, 1st ed. Murray, London.

Dawkins R. 1976. The selfish gene. Oxford University Press, Oxford.

Deacon T. 1997. The symbolic species: The coevolution of language and the brain. Norton, New York.

Dennett D. 1991. Consciousness explained. Little, Brown, New York.

Dennett D. 1995. Darwin's dangerous idea: Evolution and the meanings of life. Simon and Schuster, New York.

Dennett, D. 2006. Breaking the spell: Religion as a natural phenomenon. Viking Penguin, New York.

Dennett D. 2009. Darwin's "strange inversion of reasoning." Proc Natl Acad Sci 106: 10061-10065.
Fitch WT. 2007. Language: An invisible hand. Nature 449: 665-667.

Haig D. 2006. The gene meme. In Richard Dawkins. How a scientist changed the way we think (ed. A Grafen and M Ridley), pp. 50-65. Oxford University Press, Oxford.

Jackendoff R. 2002. Foundations of language: Brain, meaning, grammar, evolution. Oxford University Press, New York.

Lieberman E, Michel JB, Jackson J, Tang T, Nowak MA. 2007. Quantifying the evolutionary dynamics of language. Nature 449: 713-716.

Lovins A. 2002. TED (Technology, Entertainment, Design) Talk: Ideas Worth Spreading, February, 2002, Monterey, CA.

MacCready P. 1999. An ambivalent Luddite at a technological feast. Designfax, August 1999 (http://www.designfax.net/ archives/0899/899trl_2.asp).

Maynard Smith J, Szathmary E. 1995. The major transitions in evolution. Freeman, Oxford.

Pagel M, Atkinson QD, Meade A. 2007. Frequency of word-use predicts rates of lexical evolution throughout Indo-European history. Nature 449: 717-720.

Richerson P, Boyd R. 2006. Not by genes alone: How culture transformed human evolution. University of Chicago Press, Chicago, Illinois.

Rogers DS, Ehrlich PR. 2008. Natural selection and cultural rates of change. Proc Natl Acad Sci 105: 3416-3420.

Stroop JR. 1935. Studies of interference in serial verbal reactions. J Exp Psychol 18: 643-662.

Williams GC. 1966. Adaptation and natural selection. Princeton University Press, Princeton, New Jersey. 


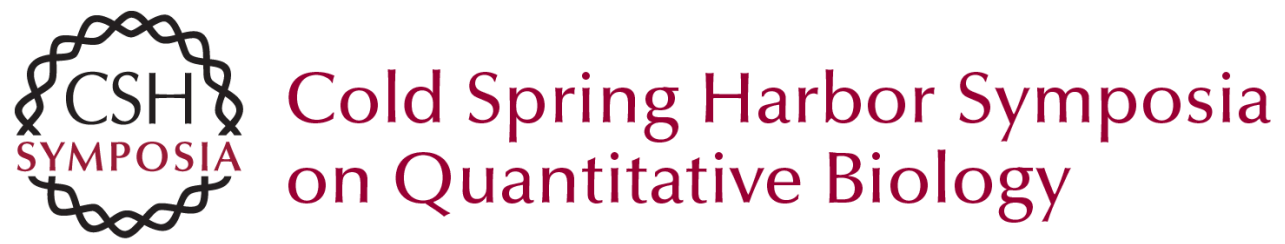

\section{The Cultural Evolution of Words and Other Thinking Tools}

D.C. Dennett

Cold Spring Harb Symp Quant Biol 2009 74: 435-441 originally published online August 17, 2009 Access the most recent version at doi:10.1101/sqb.2009.74.008

References This article cites 7 articles, 2 of which can be accessed free at: http://symposium.cshlp.org/content/74/435.full.html\#ref-list-1

License

Email Alerting Receive free email alerts when new articles cite this article - sign up in the box at the Service top right corner of the article or click here.

To subscribe to Cold Spring Harbor Symposia on Quantitative Biology go to: http://symposium.cshlp.org/subscriptions 